\title{
Development of copper price from July 1959 and predicted development till the end of year 2022
}

\author{
Marek VOCHOZKA ${ }^{1 *}$, Eva KALINOVÁ2, Peng GAO ${ }^{3}$ and Lenka SMOLÍKOVÁ4
}

\begin{abstract}
Authors' affiliations and addresses:
${ }^{1}$ Institute of Technology and Business in České Budějovice, School of Expertness and Valuation, Okružní 517/10, 37001 České Budějovice, Czech Republic

e-mail: vochozka@mail.vstecb.cz

${ }^{2}$ University of Žilina, The Faculty of Operation and Economics of Transport and

Communications, Department of Economics,

Univerzitná 8215-1, 01026 Žilina, Slovakia

e-mail: kalinova@mail.vstecb.cz

${ }^{3}$ Chongqing University of Technology, Department of Accounting, Hongguang Street, Banan District, 400054 Chongqing, P. R. China e-mail: gaopeng@cqut.edu.cn

${ }^{4}$ Brno University of Technology, Faculty of Business and Management, Department of Informatics, Kolejní 2906/4, 61200 Brno, Czech Republic

e-mail: smolikova@fbm.vutbr.cz

*Correspondence:

Marek Vochozka, Institute of Technology and Business in České Budějovice, School of Expertness and Valuation, Okružní 517/10, 37001

České Budějovice, Czech Republic tel.: +420725007337

e-mail: vochozka@mail.vstecb.cz
\end{abstract}

\section{How to cite this article:}

Vochozka, M., Kalinová, E., Gao, P. and Smolíková, L. (2021). Development of copper price from July 1959 and predicted development till the end of year 2022. Acta Montanistica Slovaca, Volume 26 (2), 262-280.

DOI:

https://doi.org/10.46544/AMS.v26i2.07

\begin{abstract}
The increasingly meagre copper ore resources constitute one of the decisive factors influencing the price of this commodity. The demand for copper has been showing an accelerating trend since the Covid pandemic broke out. It is thereby imperative to estimate the future price movement of this material. The article focuses on a daily prediction of the forthcoming change in prices of copper on the commodity market. The research data were gathered from day-to-day closing historical prices of copper from commodity stock COMEX converted to a time series. The price is expressed in US Dollars per pound. The data were processed using artificial intelligence, recurrent neural networks, including the Long Short Term Memory layer. Neural networks have a great potential to predict this type of time series. The results show that the volatility in copper price during the monitored period was low or close to zero. We may thereby argue that neural networks foresee the first three months more accurately than the rest of the examined period. Neural structures anticipate copper prices from 4.5 to 4.6 USD to the end of the period in question. Low volatility that would last longer than one year would cut down speculators' profits to a minimum (lower risk). On the other hand, this situation would bring about balance which the purchasing companies avidly seek for. However, the presented article is solely confined to a limited number of variables to work with, disregarding other decisive criteria. Although the very high performance of the experimental prediction model, there is always space for improvement - e.g. effectively combining traditional methods with advanced techniques of artificial intelligence.
\end{abstract}

\section{Keywords}

Copper price, neural networks, time series, future trend, commodity

(C) 2021 by the authors. Submitted for possible open access publication under the terms and conditions of the Creative Commons Attribution (CC BY) license (http://creativecommons.org/licenses/by/4.0/). 


\section{Introduction}

The trade of copper has increasingly assumed substantial significance on the commodity market. The year 2016 saw a rise in exporting copper ores, concentrates, copper stones, and cement copper by $1.5 \%$, achieving USD 47.3 bill, while the import reached USD 43.9 bill (Comtrade, U. N., 2016). The average rates of copper mining ranged from $0.5 \%$ to $2 \%$ of $\mathrm{Cu}$ in 2010, which, for economic reasons, hampers direct smelting. Sulfide ores thereby go through a froth flotation process to gain concentrates containing $\approx 30 \% \mathrm{Cu}$, converting concentrates to main products offered by copper mining companies (Glöser, Soulier \& Tercero-Espinoza, 2013). The market with negotiable copper concentrates lacks tangible references, public official or regulated markets which would provide stockholders with a practical guide to set a reference official price of the concentrates - yet, this information exists for basic commodities included in the concentrate (Díaz-Borrego et al., 2021). Copper concentrates are jointly negotiated between tradesmen and mining companies all over the world, which currently presents the principal source of refined copper, and as of 2017, it represents $67 \%$ of global production. On the other hand, SX-EW constitutes $16 \%$, and secondary copper processing amounts to $17 \%$ of the global production (International Copper Study Group, 2018). The prediction of prices of copper was a subject of various surveys.

Díaz-Borrego, Miras-Rodríguez \& Escobar-Pérez (2019) point out a serious gap in the research on the price for which mining companies sell copper concentrates to smelters. The situation on the market is even more complicated as smelters receive negotiable copper from a concentrate produced by mining companies that process extracted ore. It is thereby necessary to precisely analyse the purchasing price of the concentrates bought by smelters from mining companies, except for the copper price. The evaluation of copper concentrates is a fundamental task carried out by miners or traders who follow processes involving market prices of copper and other precious metals such as gold, silver and also price mark-downs or coefficients, which usually comprise the highest part of yields received from negotiating for concentrates, smelting or refining (Vochozka \& Horák, 2019). The main deductions of the market value of the metal contained in concentrates involve charges for the processing of copper (TC), charges for refinement of copper (RC), proviso on the price participation (PP) and liability to fines for criminal elements. Brabenec et al. (2020) consider the volatility in prices of metals to be the most effective criterion to evaluate worthwhile mining projects. Good command of volatility in metal prices can thereby help managers and shareholders of mining projects make sensible decisions either to nurture or limit their mining ambitions. Unfortunately, conventional methods tend to unreliably estimate the rapid price volatility of metals, as they have recently been subject to dramatic changes (Machová, Krulický \& Horák, 2020). Therefore, it is necessary to use artificial algorithms, which can precisely predict the prices of copper. Wang et al. (2019) agree that prices of copper on international markets are unsteady, and an accurate prediction may hold a useful clue as to negotiate commodities and generate profits in the copper industry. The prognosis of prices of metals is imperative in various economic aspects, contributing to financial models for monitoring incomes, which constitute an effective pay-roll scheme used by resource policy creators Liu et al. (2017).

The article intends to determine the future development of the time series of copper prices until the end of 2022 based on previous price behaviour. The research questions are as follows:

RQ1: What is the price volatility of copper in the period from July 1959 to the end of April 2021 ?

RQ2: What will be the price movement of copper from May 2021 to December 2022?

RQ3: What will be the volatility of the price movement of copper from May 2021 to December 2022?

\section{Literature Review}

A rapidly growing mass of data and technological development brings about continuous changes in the financial market, so that modelling and predicting time series comprise crucial data analysis methods that allow wiser decision-making on investments and risk management $(\mathrm{Ni}, 2019)$. Predicting time series data is an essential issue in economics, entrepreneurship and financing (Šulěr, Rowland \& Krulický, 2021). There are several techniques to effectively foresee the next time series delay, e.g. Univariate Autoregressive (AR), Univariate Moving Average (MA, Simple Exponential Smoothing (SES) and Autoregressive Integrated Moving Average (ARIMA), the last including a lot of variations (Siami-Namini, Tavakoli \& Siami Namin, 2018). Liu et al. (2017) used a machine learning algorithm based on the decision tree of copper price to predict the future movement. Their method was able to correctly and reliably anticipate prices of copper on a short-term (days) and long-term (years) basis with the mean percentage error not exceeding $4 \%$. The experiment also proved that the current method is robust, objective and free of human bias. The approach is thereby applicable for predicting prices of other metals and other commodities as well and is likely to be useful in a wide range of professional fields. Copper price often depends on the global economy, supply and demand, production costs, current exchange rate of the dollar and other factors, which even more underline their inclination to unsteadiness and fluctuation. On the other hand, enterprises producing and processing non-ferrous metals usually spend more than $60 \%$ of overall costs on raw materials (Sharma, Saxena \& Vagrecha, 2015). For a lot of companies in the mineral industry, including without limitations metallurgy and metal processing, metal is an essential produced material and price movements of 
metals have a severe impact on their earnings (Chen et al., 2016). Various economic, geopolitical and technological factors influence prices of commodities either positively or negatively. These inconsistent price and market trends are hard to predict and require an accurate prognosis based on stochastic approaches combined with traditional methods, e.g. time series and econometric techniques (Tapia Cortez et al., 2018).

Astudillo et al. (2020) compared the potential of SVR - a regressive method of supporting vectors Support Vector Regression (SVR) with external repetitions of predicting the final price of copper on London Metal Exchange 5, 10, 15, 20 and 30 days in advance. The best model of individual prognosis interval used a grid searching method and balanced cross-validation. The experiments on actual data sets suggest that parameters (C, $\varepsilon, \mathrm{y})$ of the support vector regression of the model are not different among various prediction intervals. A large number of previous values used for estimations are not contrasting even within the estimated interval. The results show that the regressive model of supporting vectors has a lower prediction error and is more robust. The findings also suggest that the presented model can accurately forecast the price volatility of copper because the root mean square error (RMSE) was the same or lower than $2.2 \%$ for the prediction period of 5 and 10 days.

Alipour, Khodayar and Jafari (2019) evaluated various prediction methods within econometrics and financial management. They applied techniques such as ARIMA, TGARCH and stochastic differential equations in time series predicting monthly prices of copper. The effectiveness of these approaches was tested even in predicting the time series of monthly prices of copper from 1987 until the end of 2014. The results show that the average of about one thousand runs using Stochastic Differential Equations (SDE) within 33 cases provide better prediction outcomes of prices of copper than traditional linear or non-linear techniques (ARIMA or TGARCH) modelling the price movement. Carrasco et al. (2018) examined the potential of artificial neural networks (ANN) and ANN predicting chaotic time series of prices of copper - all based on different combination structures and familiarity with large analysed data sets. The experiment comprised two models of neural networks predicting copper price on London Metal Exchange (LME) using algorithm Feed Forward Neural Network (FFNN) and Cascade Forward Neural Network CFNN) combining training, transfer and performance functions in MatLab. The obtained findings proved that ANN is best used in the financial prognosis of prices of copper. Predicting prices of copper with the use of various masses of data input may be improved by a different number of neurons or changing the transfer or performance function.

Kulkarni and Haidar (2009) focused on feed-forward neural networks presenting a model of a multi-layer feed-forward neural network for predicting the spot price of oil on a short-term basis - three days forward. Seeking the optimal ANN model, the authors had tested several methods of data pre-processing. Lasheeras et al. (2015) explored the performance of ARIMA and other two models of artificial neural structures (multi-layer perceptron and Elman) through published data on the spot prices of copper from the New York Commodity Exchange (COMEX). The acquired empirical results showed a better performance of both models compared to ARIMA. The experiment supports the findings of previous studies confirming the superiority of the analysed neural networks over ARIMA models in relative research areas. Adebiyi, Adewumi \& Ayo (2014) underline the discovery by comparing the prediction performance of ARIMA and an artificial neural network model with the published data on shares from the New York Stock Exchange. The achieved empirical results also proved the dominance of the neural network model over ARIMA. In spite of all the suggested advantages of artificial neural structures, their performance within specific real-time series is not satisfactory. Improving the prediction, including without limitations time series prognoses, is a crucial yet difficult task to get to grips with.

Khashei Bijari (2010) argues that theoretical and empirical findings suggested that the integration of different models can effectively enhance the prediction performance, especially if the data set models are clearly contrasting. These reasons gave grounds to a new hybrid model of artificial neural networks based on models of autoregressive integrated moving average (ARIMA) to achieve a more accurate prediction model. Empirical results of three wellknown real data sets show that the proposed model may increase the prediction accuracy, so far provided by artificial neural networks. The model is a useful alternative for making predictions, particularly if a correct forecast is required. Kriechbaumer et al. (2014) explored an upgraded combined approach wavelet-autoregressive integrated moving average (ARIMA), foreseeing monthly prices of aluminium, copper, lead and zinc. The prediction accuracy of ARIMA models dramatically increases by wavelet multi-resolution analysis (MRA) before adapting to ARIMA. The method involves the optimum combination of wavelet transformation, wavelet function and a number of decay levels used in MRA to improve the accuracy substantially. The results indicated that the proposed framework could increase the prognosis correctness one month in advance by $53 \$ / \mathrm{t}$ for aluminium 126 $\$ / \mathrm{t}$ for copper, $50 \$ / \mathrm{t}$ for lead and $51 \$ / \mathrm{t}$ for zinc compared to conventional ARIMA methods.

Abraham et al. (2021) forecast by the harvesting area, income and production of soya beans using artificial neural networks (ANN) compared to traditional methods of analysing time series. The authors collected data about soya production in Brasil between 1961 and 2016. The results indicate that ANN is the best technique of predicting the harvesting areas and soya production, whereas a conventional linear function is more effective to anticipate soya yields. Moreover, ANN presents a reliable model of foreseeing the time series that can help with the prediction of the future global supply of soya. Kurumatami (2020) explored agricultural commodities regarding their future price. The author devised a method of forecasting time series for future prices of agricultural products, 
laying down criteria for evaluating predicted time series in terms of statistical characteristics. The prices of agricultural commodities are highly seasonal, and conventional techniques such as autoregressive integrated moving average (ARIMA and Box Jenkins method) did not appear to be very useful for the prediction. Recurrent neural networks (RNN) with a new technology of machine learning (ML) can anticipate time series more precisely than their conventional counterparts. Two methods of generating future time series TATP (Time-alignment of time point forecast) and DFTS (Discrete-time Fourier series), originated. Both approaches use unique RNN, including LSTM (Long-short term memories), GRU (Gated recurrent unit) for making prognoses. They can also apply simple RNN. The research heavily focused on the accuracy, including error rate in RMS - Root Mean Square and MA - Moving Average and the performance of statistical characteristics involving a continuous probability distribution, such as Lévy distribution.

Sezer, Gudelek \& Ozbayoglu (2020) reviewed relevant studies, outlining the current state of DL (Deep Learning) for predicting financial time series. The studies comprised individual assets together with a preferred DL model dealing with the problem. The findings reveal that although financial prognoses have long been subject to thorough research, the demand among the DL community is growing thanks to the wide applicability of new DL models; there are thus many opportunities for further research. Vochozka (2017) explored the regressive analysis of the price movement of palladium on The New York Stock Exchange by comparing only two statistical instruments. The curve produced by the least square method using negative exponential smoothing showed the best characteristics out of all linear regressions; all preserved structures from neural networks were applicable in practice. When looking at the performance of the correlation coefficient, only neural networks which do not reflect any difference will remain.

Comparative studies focusing on algorithms demonstrated that LSTM delivers the most accurate performance (low error rate) and characteristic statistical performance only if the structure had been systematically trained by a sufficient number of learning periods in the right direction. Simple RNN as a general method of linear modelling showed better performance in the error rate than GRU and LSTM with a smaller number of learning periods. However, a comprehensively trained LSTM demonstrated higher performance than simple linear methods SRNN (Simple recurrent neural network (Kurumatami, 2020). Kamdem, Essomba \& Berinyuy (2020) argue that applied models of deep learning have recently captured the attention of investors and researchers, who used a deep learning model and LSTM for predicting commodity prices. The obtained results accurately foresee prices of commodities, including oil (price 98.2; commodity price variability 88.2). Ly, Traore \& Dia (2021) applied recurrent neural networks to forecast time series using the RNN method to anticipate cotton and oil prices. Their experiment showed how to successfully combine new machine learning techniques (including without limitations LSTM) with traditional approaches.

The results indicate that methods of machine learning efficiently process the data yet do not overcome traditional techniques such as ARIMA models as far as prognoses outside the sample are concerned. However, averaging the prognoses of two types of models provides better results as contrasted to both methods. Compared to ARIMA and LSTM, the root means square error (RMSE) of an average prediction of the cotton price lowered by 0.21 and $21.49 \%$. On the other hand, RMSE does not show any improvement in the average forecast of oil prices. Siami-Namini, Tavakoli \& Siami Namin (2018) also contrasted traditional ARIMA models with LSTM model networks and revealed that algorithms based on deep learning, such as LSTM, surmount conventional algorithms, such as ARIMA. To put it more precisely, the average error lowering obtained by LSTM was between 84 and $87 \%$ as contrasted to ARIMA, which demonstrates LSTM predominance. Further findings suggested that the number of training times, known as 'periods', in the deep learning did not bear any influence on the performance of the training prediction model, thus exhibiting randomness only. Based upon this knowledge, LSTM is the best method for analysing and predicting the time series of prices of copper on the commodity market.

\section{Materials and Methods}

The data for the analysis are available from Macrotrends (2021). The data are available for each trading day from the $2^{\text {nd }}$ July 1959 to $28^{\text {th }}$ April 2021 . The closing price of the day will be taken.

The formulated research questions assume the examination of time series volatility, smoothing, and prediction of its future development and volatility. However, the question is whether it is appropriate to use the data of the whole time series or only its part, to obtain a relevant result. Neural networks which use the LSTM layer also have the forget gate; nevertheless, it is not sure whether, despite this function, the result of the neural network will not be distorted by the information from the beginning of the time series development (Vochozka, Vrbka \& Šuleř, 2020). To find the answer to RQ1, the entire time series in the period 1959-2021 will be used. In the case of RQ2, however, we will use an experiment where in one part of it, the whole period will be considered; in the second part, the procedure will be the same, only with a significantly shorter time series, specifically a two-year period (from $29^{\text {th }}$ April 2019 to $28^{\text {th }}$ April 2021). The basic characteristics of both time series are presented in Table 1. 
Tab. 1. Characteristics of time series of copper prices intended for predicting its future development

\begin{tabular}{|c|c|c|}
\hline Characteristics & Copper price in the years $1959-2021$ & Copper price in the years 2019-2021 \\
\hline Mean value & 1.316703 & 2.81593 \\
\hline Standard error of mean & 0.008462 & 0.028215 \\
\hline Median & 0.8325 & 2.7 \\
\hline Modus & 1 & 2.4 \\
\hline Standard deviation & 1.052575 & 0.634052 \\
\hline Variance & 1.107914 & 0.402022 \\
\hline Kurtosis & 0.412255 & 0.429509 \\
\hline Skewness & 1.271432 & 0.987279 \\
\hline Difference of max-min & 4.6828 & 2.9 \\
\hline Minimum & 0.2672 & 2 \\
\hline Maximum & 4.95 & 4.9 \\
\hline Sum & 20372.03 & 1422.045 \\
\hline Number & 15472 & 505 \\
\hline The biggest (1) & 4.95 & 4.9 \\
\hline The lowest (1) & 0.2672 & 2 \\
\hline Confidence level $(95.0 \%)$ & 0.016587 & 0.055433 \\
\hline
\end{tabular}

The response to RQ3 will be obtained based on the prediction of the best generated neural network.

Time series volatility (RQ1). Through the examination of annual volatility, the time series is calculated as follows:

where

$$
\sigma_{T}=\sigma \sqrt{T}
$$

$\sigma_{T}$ is the annual volatility of copper,

$T$ time (one year),

$\sigma \quad$ standard deviation.

The resulting value will be graphically illustrated.

Prediction of future development of copper price (RQ2). An artificial neural network ("NN) which will contain Long Short Term Memory (hereinafter also referred to as "LSTM") The layer will be generated by means of an experiment. The experiment consists of the different settings of three NN parameters:

1. The number of elements in the matrix based on the LSTM layer.

2. Activation functions (in the form of Elementwise Layer), which will be used for the propagation of the signal between the individual NN layers. Specifically, the following activation functions will be used: hyperbolic tangent, inverse tangent, inverse hyperbolic tangent, sine, ramp (sometimes also referred to as ReLu - Rectified Linear Unit), and logistic function.

3. Time series lag, i.e. a sequence of previous values based on which the future values are predicted. The considered lag will be determined to 10, 20, and 30 days.

The structure of the NN will be the same in all cases (except for the changing parameters mentioned above). The diagram of the $\mathrm{NN}$ is shown in Figure 1.

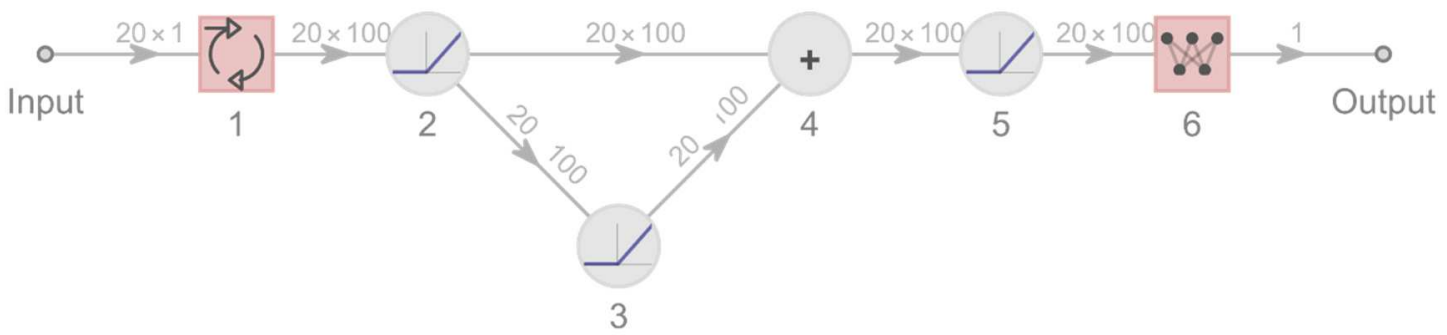

Fig. 1. Structure of NN with LSTM layer

The NN consists of 8 layers, where two of them - input and output layer - are not assigned a number. The remaining six layers are considered the hidden layers.

1. The input layer of neurons: consists of a matrix containing information about the copper price. Figure 1 indicates it is a matrix $20 \times 1$; in fact, two more matrices, $10 \times 1$ and $30 \times 1$ will be tested within the experiment. The value $\mathrm{m}$ in the matrix indicates how many consecutive variables are necessary for calculating the next variable.

2. $\quad 1^{\text {st }}$ hidden layer of neurons: it consists of the LSTM layer; the output is a matrix $m \times n$, where $m$ is time series lag, and $n$ is a defined number of elements in matrix determined by the experiment, with 
the values of 10-2000 (for simplification, the figure shows a matrix $20 \times 100$, i.e. the matrix at the input LSTM $20 \times 1$ will generate a matrix $20 \times 100$ at the output)). The step for $\mathrm{n}$ will be 1 .

3. $2^{\text {nd }}$ hidden layer: it is Elementwise Layer (a simple network working with perceptron). The activation functions for individual generated $\mathrm{NN}$ will be randomly selected from the activation functions specified above.

4. $\quad 3^{\text {rd }}$ hidden layer: it is an Elementwise Layer with the same setting as in the case of the Elementwise Layer in the $2^{\text {nd }}$ hidden layer.

5. 4th hidden layer of neurons: determined as Plus; it sums the values (signal) it will receive from the $2^{\text {nd }}$ and the $3^{\text {rd }}$ hidden layer and send it to the $5^{\text {th }}$ hidden layer.

6. $5^{\text {th }}$ hidden layer of neurons: Elementwise Layer with the same setting as in the case of the Elementwise Layer in the $2^{\text {nd }}$ hidden layer.

7. $6^{\text {th }}$ hidden layer of neurons: Linear Layer with a data matrix at the input (the figure presents the matrix $20 \mathrm{x} 100)$. The output of the layer is a vector with one element.

8. Output layer: predicted copper price.

Long-Short Term Memory Layer. The first hidden neural network consists of LSTM. LSTM can be an individual NN; in this case, however, it represents one layer only. It is a sophisticated recurrent NN whose structure is made up of four basic blocks: input gate, output gate, forget gate, and memory gate. The new state of the cell (prediction) is defined as follows:

where

$$
c_{t}=f_{t} * c_{t-1}+i_{t} * m_{t} \text {, }
$$

$c_{t} \quad$ is a new state of the variable,

$f_{t} \quad$ forget gate,

$c_{t-1} \quad$ the initial state of the variable,

$i_{t} \quad$ input gate,

$m_{t} \quad$ memory gate.

Input gate is defined as follows:

where

$$
i_{t}=\sigma\left[W_{i x} x_{t}+W_{i s} s_{t-1}+b_{i}\right]
$$

$\sigma \quad$ is Logistic Sigmoid,

$W_{i x} \quad$ is an input weight in the input gate, matrix $n \times k$,

$x_{t} \quad$ is an input variable, matrix $n \times k$,

$W_{i s} \quad$ weight of the state in the input gate, matrix $n \times n$,

$s_{t-1} \quad$ the initial state,

$b_{i} \quad$ bias, vector size $n$.

The state is defined as follows:

where

$$
s_{t}=o_{t} * \operatorname{Tanh}\left[c_{t}\right] \text {, }
$$

$s_{t} \quad$ is a state of the variable,

$o_{t} \quad$ output gate,

Tanh hyperbolic tangent.

Output gate is defined as follows:

where

$$
o_{t}=\sigma\left[W_{a x} x_{t}+W_{a s} s_{t-1}+b_{o}\right]
$$

$W_{a x} \quad$ defines the input weight in output gate, matrix $n \times k$,

$W_{a s} \quad$ weight of the state in output gate, matrix $n \times n$,

$b_{o} \quad$ bias, vector size $n$.

Compared to, for example, Gated Recurrent Layer, the advantage of LSTM lies in forget gate:

where

$$
f_{t}=\sigma\left[W_{f x} x_{t}+W_{f s} s_{t-1}+b_{f}\right]
$$

$W_{f x}$

is an input weight in forget gate, matrix $n \times k$, 
$W_{f s} \quad$ is the weight of the state in forget gate, matrix $n \times n$,

$b_{f} \quad$ bias, vector size $n$.

The main processes of LSTM include memory gate:

where

$$
m_{t}=\operatorname{Tanh}\left[W_{m x} x_{t}+W_{m s} s_{t-1}+b_{m}\right]
$$

$W_{m x} \quad$ defines the input weight in memory gate, matrix $n \times k$,

$W_{m s} \quad$ weight of the state in memory gate, matrix $n \times n$,

$b_{m} \quad$ bias, vector size $n$.

Algorithm ADAM - method of stochastic optimisation, adaptive moment estimation (Kingma and Ba, 2015) will be used to create three sets of neural networks for each dataset. Each set contains $1990 \mathrm{NN}$, out of which the one with the best characteristics will be selected. In this case, the characteristics will be determined based on the Pearson correlation coefficient, i.e. the relationship between the set of input variables and smoothed time series. Another parameter for determining the best NN is the economic interpretability of the results (NN must not suffer from overfitting).

After selecting NN, a prediction of the future development is made for each trading day until 31st December 2022 (inclusive).

Volatility of future development (RQ3). The procedure for determining the volatility of the future developments in the copper price will be analogous to the one used to identify the volatility of historical development. However, for this purpose, it is used the predicted data, from May 2021 to December 2022, as determined in the previous research question.

\section{Results}

Volatility of historical development. Figure 2 is a graphical representation of the volatility of the entire time series development (1959-2021) on a yearly basis. The peak is in the year 2008 when the volatility was 0.833669 , which is a very high value. The lowest level of annual volatility of the time series was recorded for the year 1963 (see Table 2) when the volatility reached its minimum of 0.00321 .

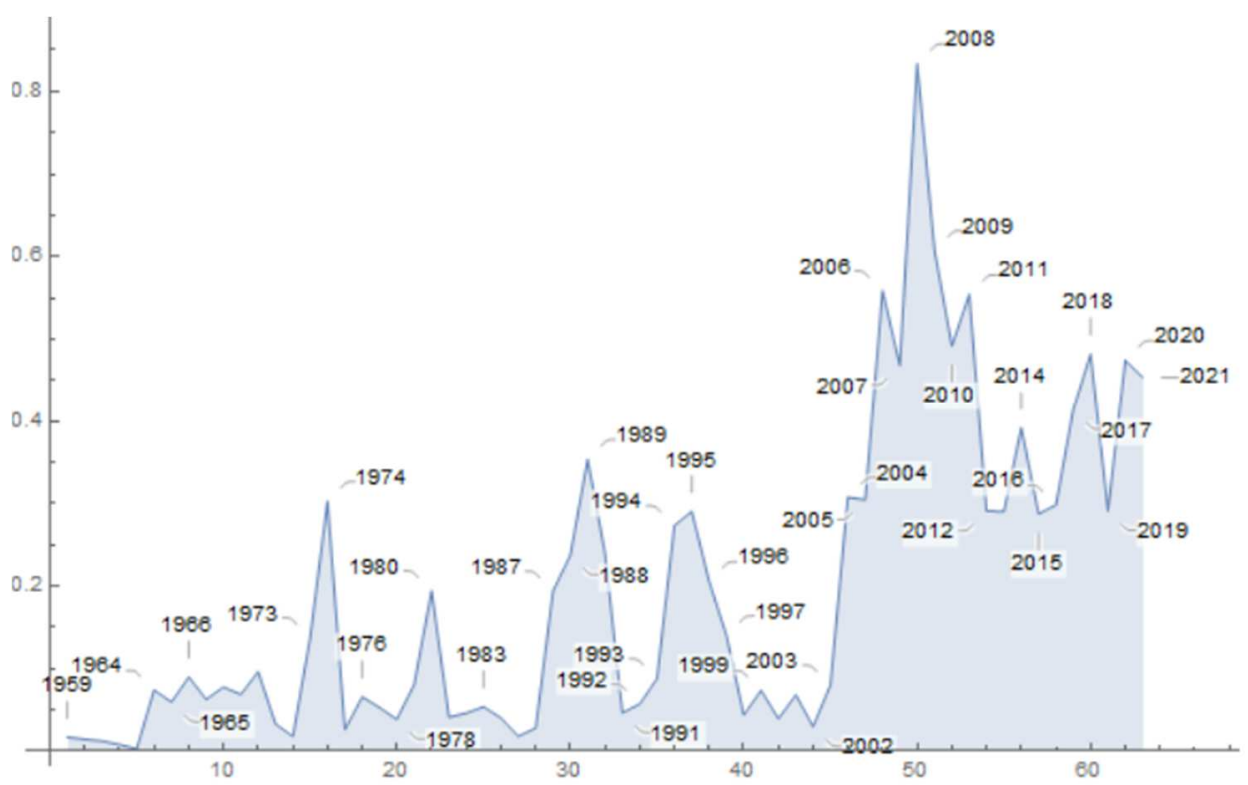

Fig. 2. The volatility of historical development of copper price time series

Table 2 shows the development of volatility on an annual basis for the period of 1959-2021. The values presented in the table are the data used for graphical representation of the volatility development in Figure 2. 
Tab. 2. Development of copper price volatility in 1959-2021

\begin{tabular}{cccccc}
\multicolumn{5}{c}{ Tab. 2. Development of copper price volatility in $1959-2021$} \\
\hline Year & Volatility & Year & Volatility & Year & Volatility \\
\hline 1959 & 0.017019 & 1980 & 0.194572 & 2002 & 0.029963 \\
1960 & 0.014613 & 1981 & 0.041435 & 2003 & 0.080282 \\
1961 & 0.012453 & 1982 & 0.046211 & 2004 & 0.307575 \\
1962 & 0.00819 & 1983 & 0.053883 & 2005 & 0.304431 \\
1963 & 0.00321 & 1984 & 0.040501 & 2006 & 0.558947 \\
1964 & 0.074264 & 1985 & 0.018181 & 2007 & 0.468099 \\
1965 & 0.059692 & 1986 & 0.028098 & 2008 & 0.833669 \\
1966 & 0.089968 & 1987 & 0.194178 & 2009 & 0.607714 \\
1967 & 0.062971 & 1988 & 0.237367 & 2010 & 0.551891 \\
1968 & 0.077824 & 1989 & 0.353545 & 2011 & 0.290891 \\
1969 & 0.068808 & 1990 & 0.239732 & 2012 & 0.290342 \\
1970 & 0.09643 & 1991 & 0.046577 & 2013 & 0.391797 \\
1971 & 0.033103 & 1992 & 0.057453 & 2014 & 0.287288 \\
1972 & 0.017924 & 1993 & 0.088123 & 2015 & 0.4140612 \\
1973 & 0.137727 & 1994 & 0.27339 & 2016 & 0.482174 \\
1974 & 0.302861 & 1995 & 0.290499 & 2017 & 0.291045 \\
1975 & 0.026252 & 1996 & 0.205737 & 2018 & 0.474418 \\
1976 & 0.065925 & 1997 & 0.14022 & 2019 & 0.453877 \\
1977 & 0.05289 & 1998 & 0.043971 & 2020 & 2021 \\
1978 & 0.038651 & 1999 & 0.073807 & & \\
1979 & 0.081153 & 2000 & 0.039484 & & \\
\hline
\end{tabular}

Prediction future copper price development. Obviously, the best results in terms of the correlation coefficient are provided by the NN with the lag of 10 trading days (for more details, see the Annex).

Time series from the year 1959. Table 3 shows the performance of five selected neural networks with a 10-day lag. The performance is very similar (high) for all types of networks; however, the best performance $(0.9869)$ shows the network 5NN10. Table X contains the number of elements in the matrix for individual networks and activation functions 1, 2 and 3. There can be seen the combination of the activation functions ArcTan, Ramp, and Sin.

Tab. 3. Basic setting of network parameters and network performance

\begin{tabular}{|c|c|c|c|c|c|}
\hline Network & Performance & $\begin{array}{c}\text { Number of Matrix } \\
\text { Members }\end{array}$ & $\begin{array}{l}\text { 1. Activation } \\
\text { Function }\end{array}$ & $\begin{array}{l}\text { 2. Activation } \\
\text { Function }\end{array}$ & $\begin{array}{l}\text { 3. Activation } \\
\text { Function }\end{array}$ \\
\hline 1NN10 & 0.986710 & 378 & ArcTan & Ramp & Sin \\
\hline 2NN10 & 0.986714 & 41 & Ramp & Sin & ArcTan \\
\hline $3 \mathrm{NN} 10$ & 0.986762 & 203 & Ramp & Ramp & Sin \\
\hline 4NN10 & 0.986798 & 230 & ArcTan & ArcTan & Sin \\
\hline 5NN10 & 0.986900 & 21 & ArcTan & Ramp & Ramp \\
\hline
\end{tabular}

The basic statistics of the actual time series and smoothed time series are presented in Table 4. The basic statistics show the minimum and maximum values, mean, standard deviation, and variance. Based on the results presented in Table 4, it can be concluded that the best performance was achieved by the network $5 \mathrm{NN} 10 \mathrm{~L}$, i.e. the network which considered a 10-day lag.

\begin{tabular}{ccccc}
\hline & Tab. 4. Statistics of actual and smoothed time series \\
\hline Copper Price in & Minimum & Maximum & Mean & Standard Deviation \\
USD & 0.2672 & 4.9500 & 1.31670 & 1.05257 \\
1NN10L & 0.2700 & 4.8300 & 1.35099 & 1.07525 \\
2NN10L & 0.2700 & 4.6100 & 1.34421 & 1.03096 \\
3NN10L & 0.2600 & 4.5500 & 1.26244 & 1.02056 \\
4NN10L & 0.3100 & 4.6600 & 1.35394 & 1.03823 \\
5NN10L & 0.2900 & 4.7000 & 1.36838 & 1.069672 \\
\hline
\end{tabular}

Figure 3 shows a graph where the development of copper prices in USD is marked red. Other curves represent time series smoothed using the five best neural networks with a 10-day lag. It is not clear from the graph which of the smoothed time series corresponds most with the development of the actual copper price; however, the evaluation above showed that the best network is 5 NN10L. 


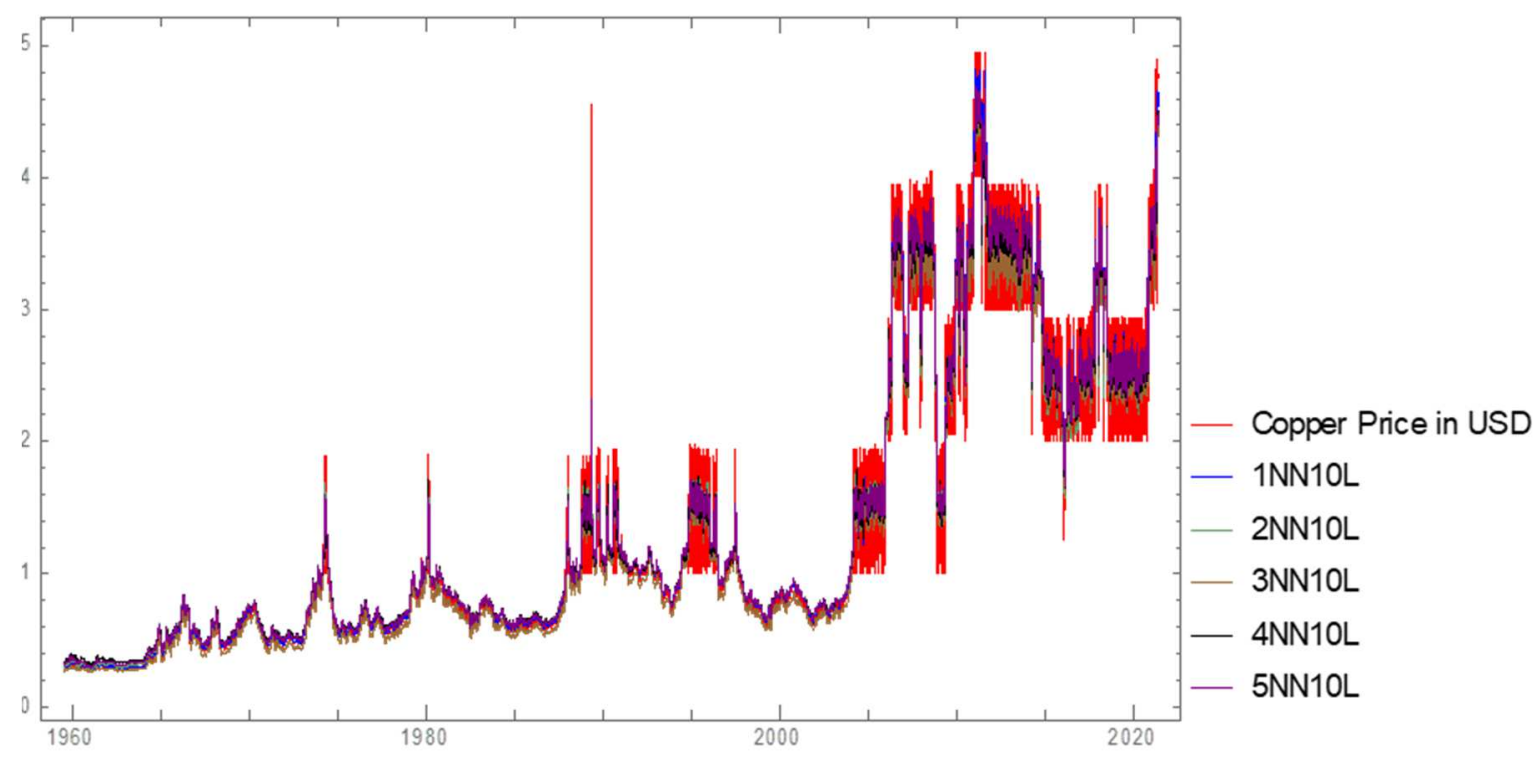

Fig. 3. Time series smoothing using all networks

It follows from the previous results, which determined the best network for smoothing the time series, that the focus will be on the network 5NN10L, especially its residuals. The graph of the 10 residual development is shown in Figure 4. It can be stated that until 2004, the range of residuals was not that wide; it is thus possible to estimate at least approximately in which periods the smoothed time series 5NN10 is most capable of predicting the actual development of the time series. After 2004, the range of residuals is very wide, and it is not possible to identify precisely the development of the residuals in this period.

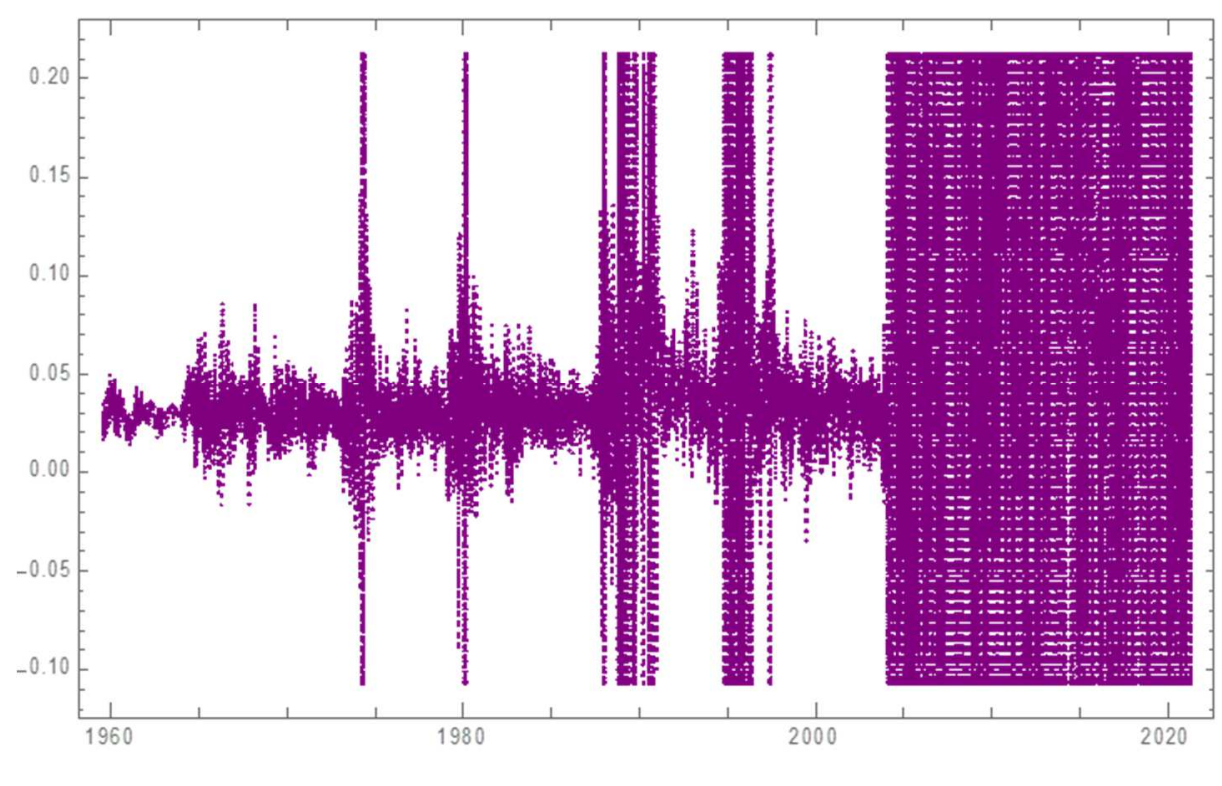

Fig. 4. 5 NN10 residuals

The prediction of the future development for each trading day until $31^{\text {st }}$ December 2022 using all five selected $\mathrm{NN}$ is shown in Figure 5. When focusing on the violet curve of the predicted development using the network $5 \mathrm{NN} 10$, the best development prediction can be seen, i.e. the development predicted using the NN with the best performance. 


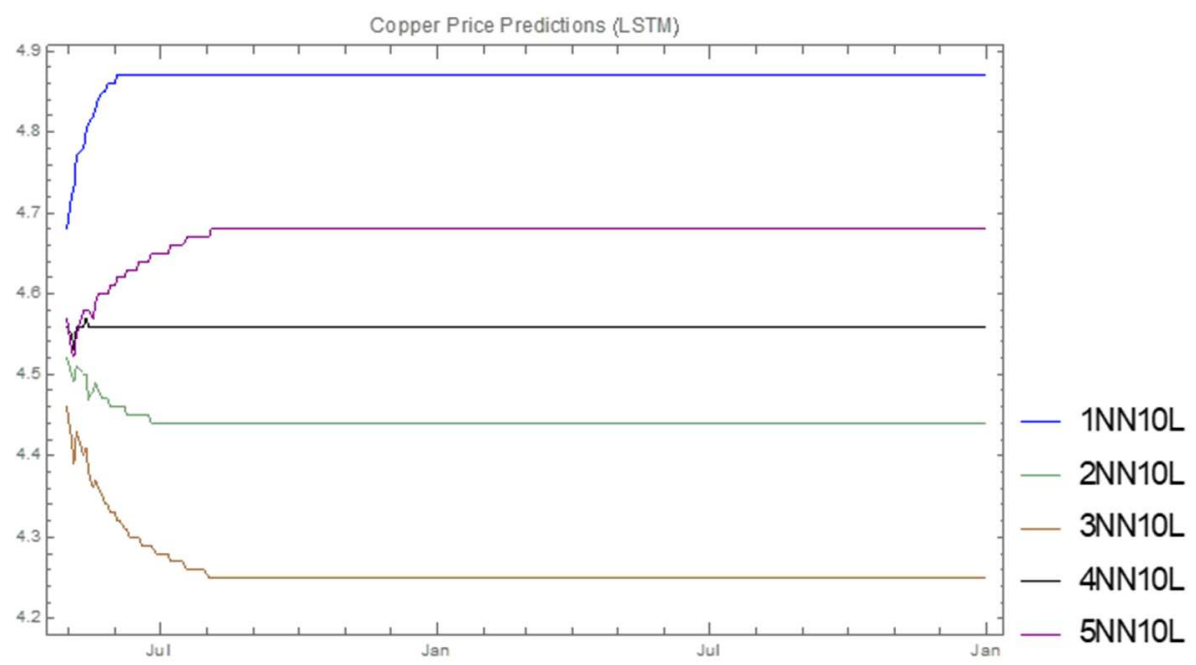

Fig. 5. Predictions of all networks

The basic characteristics of the future development prediction for each trading day until $31^{\text {st }}$ December 2022 for individual networks can be seen in Table 5 below. The basic statistics include the values of the minimum, maximum, mean, standard deviation, and variance.

\begin{tabular}{lccccc}
\multicolumn{5}{c}{ Tab. 5. Prediction statistics } \\
\hline & Minimum & Maximum & Mean & Standard Deviation & Variance \\
\hline 1NN10L & 4.68 & 4.87 & 4.86637 & 0.01986260 & 0.000394522 \\
2NN10L & 4.44 & 4.52 & 4.44293 & 0.01122230 \\
3NN10L & 4.25 & 4.46 & 4.26018 & 0.03188280 & 0.0010125940 \\
4NN10L & 4.53 & 4.57 & 4.55989 & 0.00200798 & $4.032 \times 10^{-6}$ \\
5NN10L & 4.52 & 4.68 & 4.67147 & 0.02535150 & 0.000642698 \\
\hline
\end{tabular}

Here, it is also necessary to focus on the prediction made by 5NN10L as a network with the best performance. Figure 6 shows the actual development of the time series since 1959. The following violet curve represents the development predicted using 5NN10L until 31 ${ }^{\text {st }}$ December 2022.

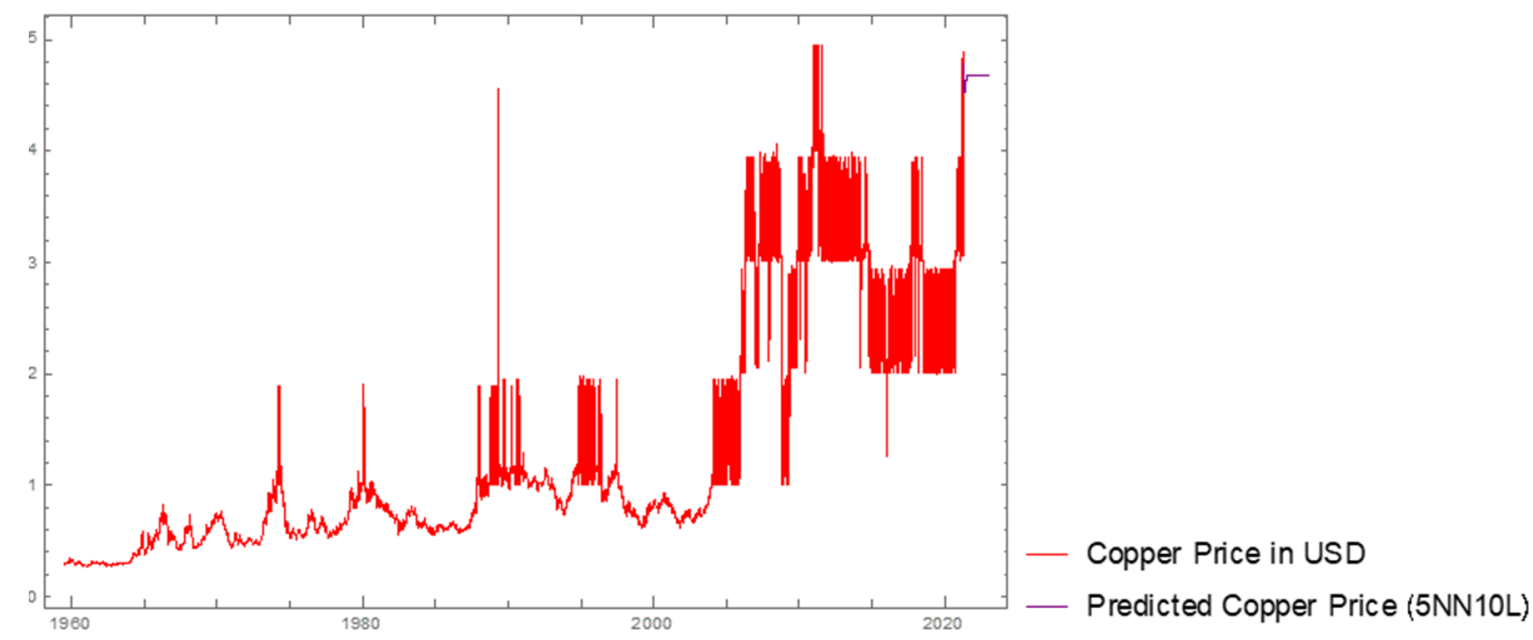

Fig. 6. 5 NN10 prediction

A more detailed development can be seen in Figure 7, which represents a more detailed prediction of the development between 30 ${ }^{\text {th }}$ March 2020 and $31^{\text {st }}$ December 2022. 


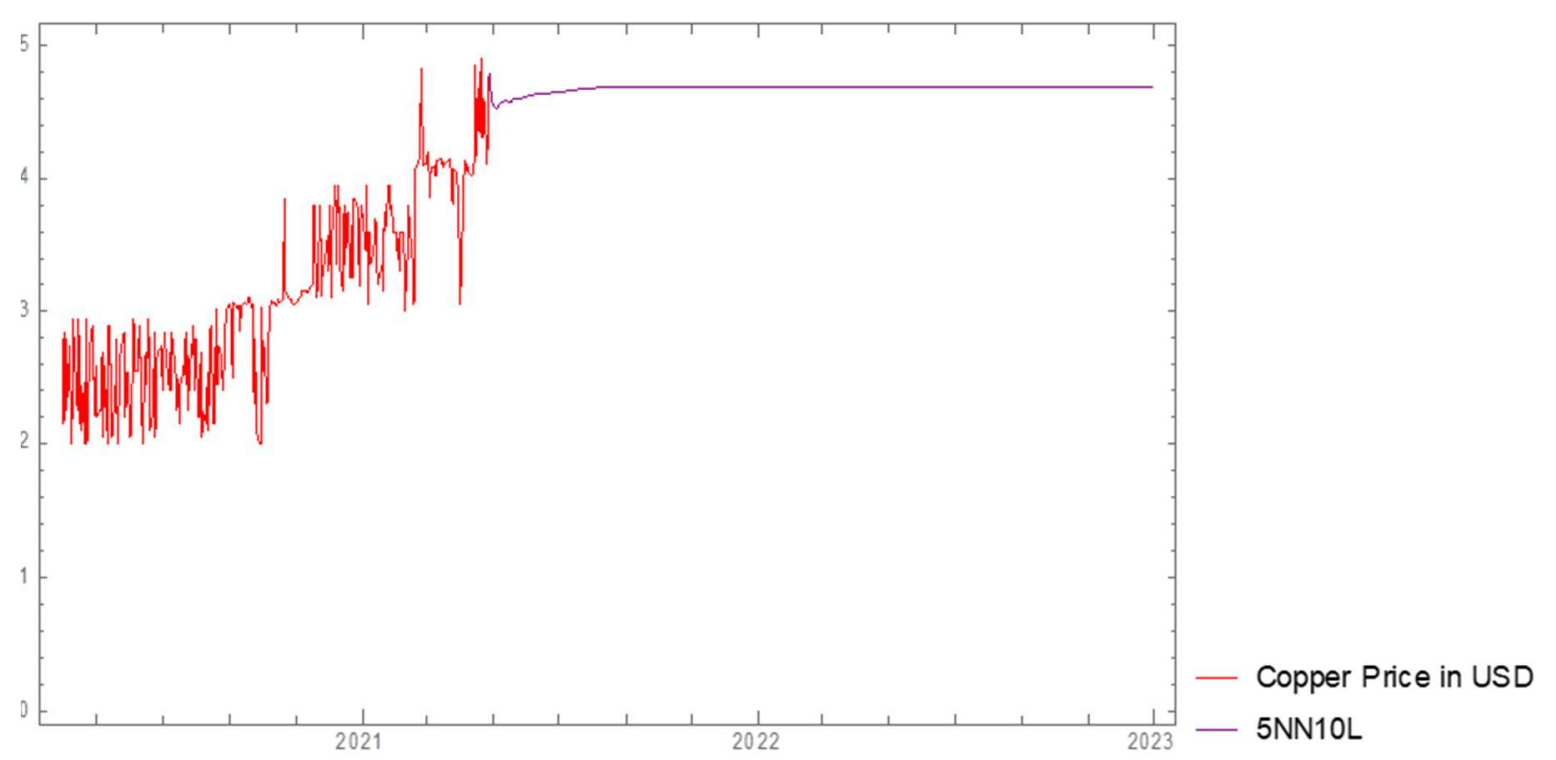

Fig. 7. Development from $30^{\text {th }}$ March 2020 to $31^{\text {st }}$ December 2022

Time series since 2019. The second experiment concerning the prediction of copper price development was carried out on a shortened time series (2019-2021). Table 6 shows the performance of the individual five most successful $\mathrm{NN}$, where the best performance was achieved by the network 5NN10 (0.923595). Compared to the first experiment carried out on the entire time series from the year 1959, there is also a different number of elements in the matrix.

Tab. 6. Basic setting of network parameters and network performance

\begin{tabular}{|c|c|c|c|c|c|}
\hline Network & Performance & $\begin{array}{c}\text { Number of Matrix } \\
\text { Members }\end{array}$ & $\begin{array}{l}\text { 1. Activation } \\
\text { Function }\end{array}$ & $\begin{array}{l}\text { 2. Activation } \\
\text { Function }\end{array}$ & $\begin{array}{l}\text { 3. Activation } \\
\text { Function }\end{array}$ \\
\hline 1NN10 & 0.916636 & 92 & Tanh & Ramp & Ramp \\
\hline 2NN10 & 0.918096 & 69 & Ramp & ArcTan & Ramp \\
\hline 3NN10 & 0.920842 & 130 & Ramp & Sin & ArcTan \\
\hline 4NN10 & 0.922938 & 87 & Ramp & Ramp & Sin \\
\hline $5 \mathrm{NN} 10$ & 0.923595 & 59 & Ramp & Tanh & Sin \\
\hline
\end{tabular}

Table 7 shows the statistics of the actual time series (Copper Price in USD) and subsequently the statistics of five best and smoothed time series $1-5 N N 10$. On the basis of the results presented in the table, it can be concluded that 5 NN10 is the best one.

\begin{tabular}{|c|c|c|c|c|c|}
\hline & Minimum & Maximum & Mean & Standard Deviation & Variance \\
\hline $\begin{array}{c}\text { Copper Price in } \\
\text { USD }\end{array}$ & 2.00 & 4.90 & 2.81593 & 0.634052 & 0.402022 \\
\hline $1 \mathrm{NN} 10$ & 2.09 & 4.69 & 2.84592 & 0.582771 & 0.339622 \\
\hline 2NN10 & 2.17 & 4.67 & 2.81176 & 0.542128 & 0.293903 \\
\hline $3 \mathrm{NN} 10$ & 2.08 & 4.83 & 2.84463 & 0.603254 & 0.363915 \\
\hline 4NN10 & 2.10 & 4.80 & 2.76202 & 0.605319 & 0.366411 \\
\hline $5 \mathrm{NN} 10$ & 2.09 & 4.55 & 2.84046 & 0.586891 & 0.344441 \\
\hline
\end{tabular}

Figure 8 shows the graph with the development of copper price in USD as a red curve and other curves representing the smoothed time series using the five best networks with a 10-day lag. It is not clear from the graph which smoothed time series best correlates with the actual development of copper price; nevertheless, based on the evaluation above, it can be concluded that the network 5NN10 is the best one. 


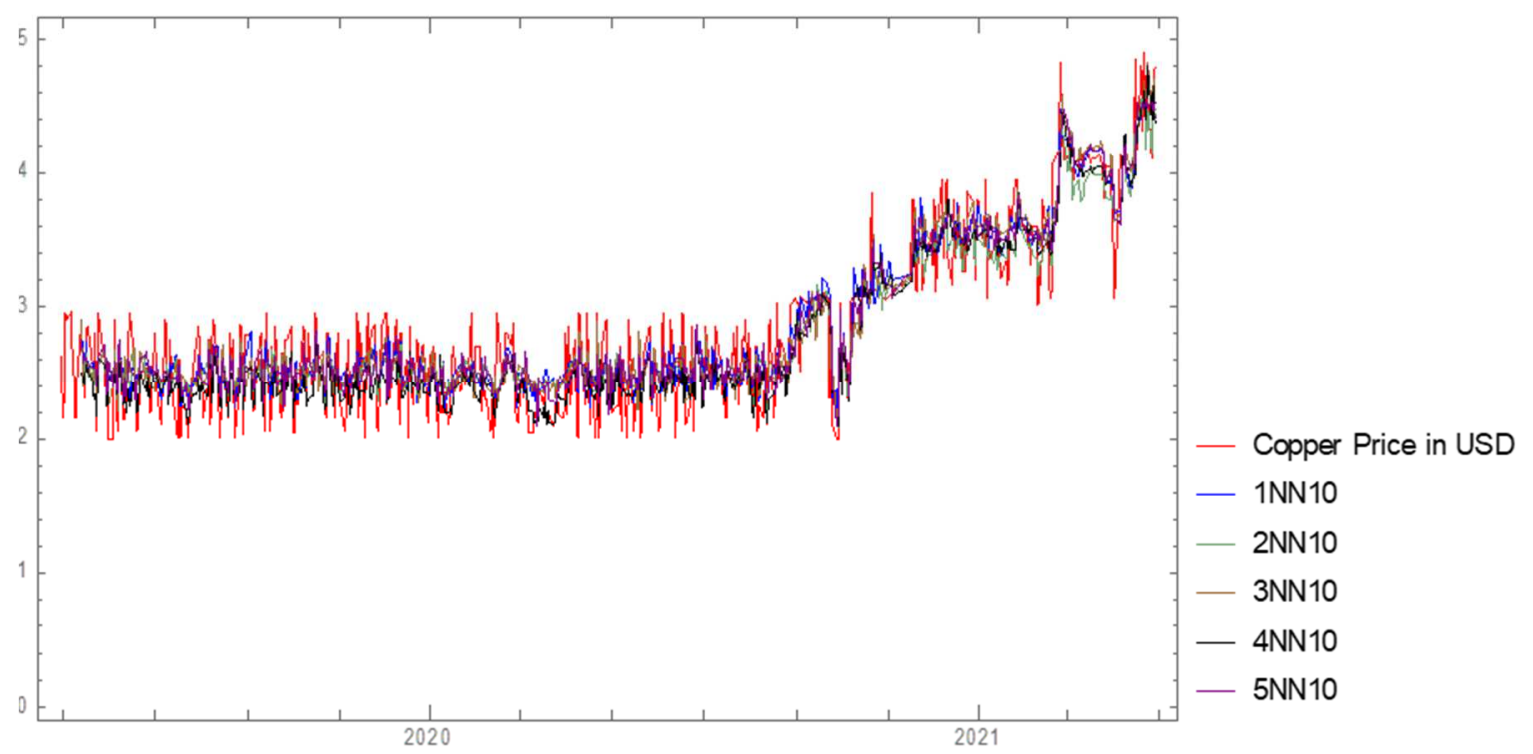

Fig. 8. Time series smoothing using all networks

At this point, it is also suitable to analyse the residuals of the network 5NN10 to determine the degree of deviation of the predicted values from the actually measured ones. The range of 5NN10 residuals is shown in Figure 9 below. Due to shortening the time series, it is possible to see the range of residuals in the monitored period (the range can be clearly seen thanks to uncondensed values). Based on Figure 9, it can be concluded that the residuals are not large.

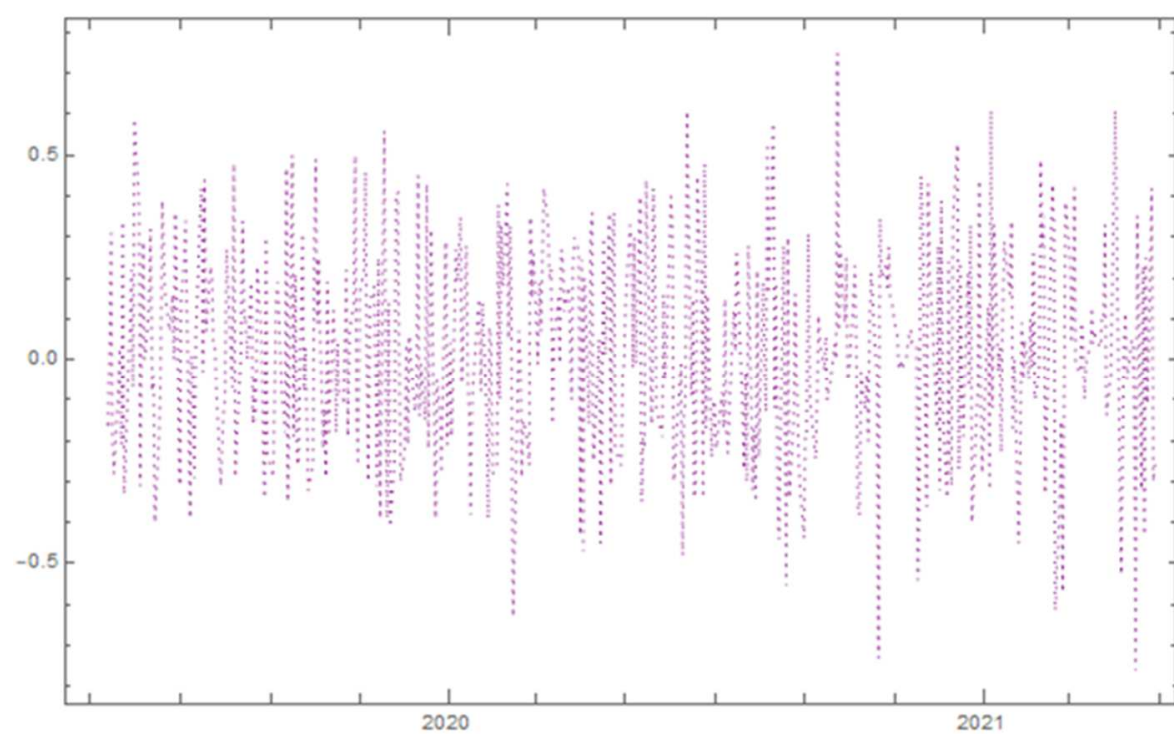

Fig. 9. 5NN10 residuals

Prediction. Prediction of the future development for each trading day until $31^{\text {st }}$ December 2022 using all five selected NN is presented in Figure 10. For the purposes of this paper, the most important appears to be the development predicted by $5 \mathrm{NN} 10$. 


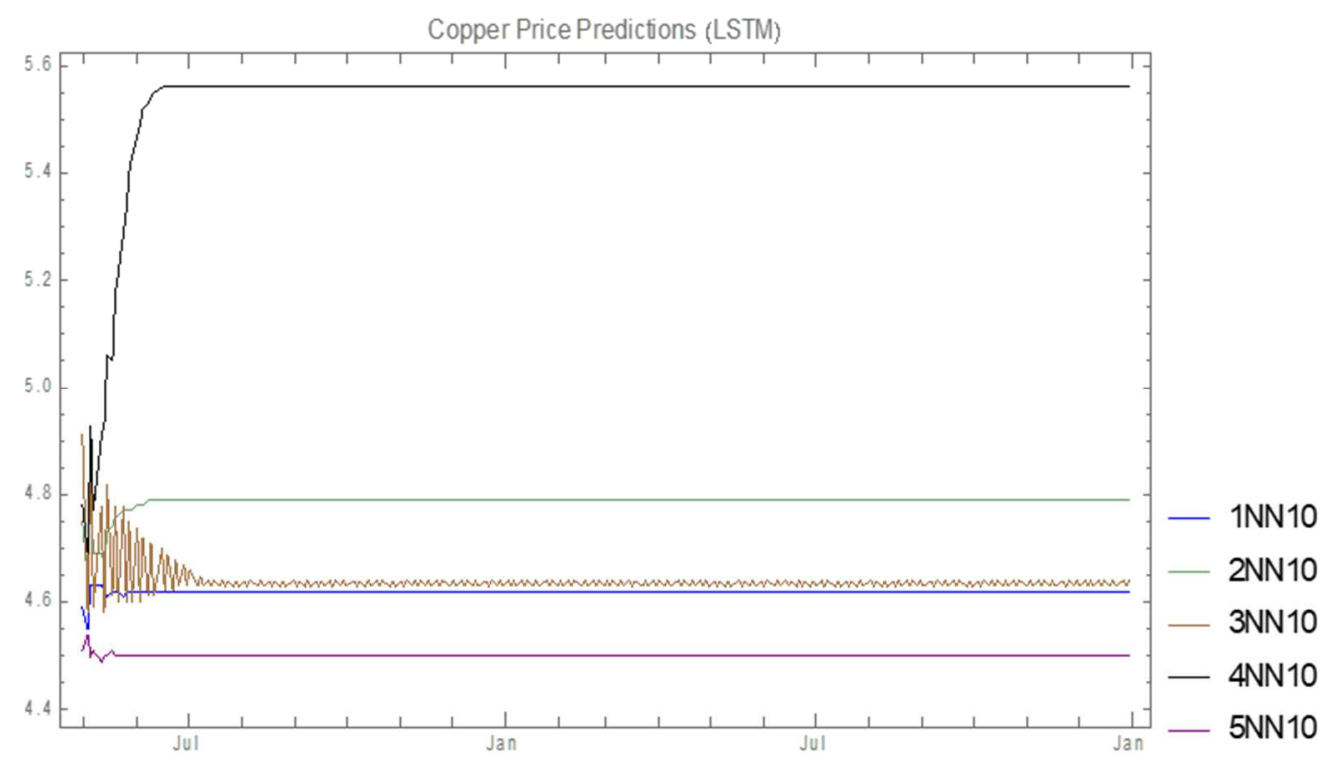

Fig. 10. Predictions of all networks

The basic statistics of future development prediction for each trading day from $1^{\text {st }}$ May 2021 to $31^{\text {st }}$ December 2022 for individual networks are presented in Table 8. The basic statistics include the values of minimum and maximum, mean, standard deviation, and variance.

Tab. 8. Prediction statistics

\begin{tabular}{lccccc}
\hline & Minimum & Maximum & Mean & Standard Deviation & Variance \\
\hline 1NN10 & 4.55 & 4.63 & 4.61967 & 0.00480132 & 0.0000230527 \\
2NN10 & 4.64 & 4.83 & 4.78725 & 0.01579270 & 0.0002494100 \\
3NN10 & 4.58 & 4.91 & 4.63993 & 0.03299950 & 0.0010889700 \\
4NN10 & 4.69 & 5.56 & 5.53385 & 0.12096800 & 0.0146333000 \\
5NN10 & 4.49 & 4.54 & 4.50022 & 0.00270268 & $7.30446 \times 10^{-6}$ \\
\hline
\end{tabular}

The development of the actual values (represented by red curve) and the predicted development from $1^{\text {st }}$ May 2021 to $31^{\text {st }}$ December 2022 using the network 5NN10 can be seen in Figure 11.

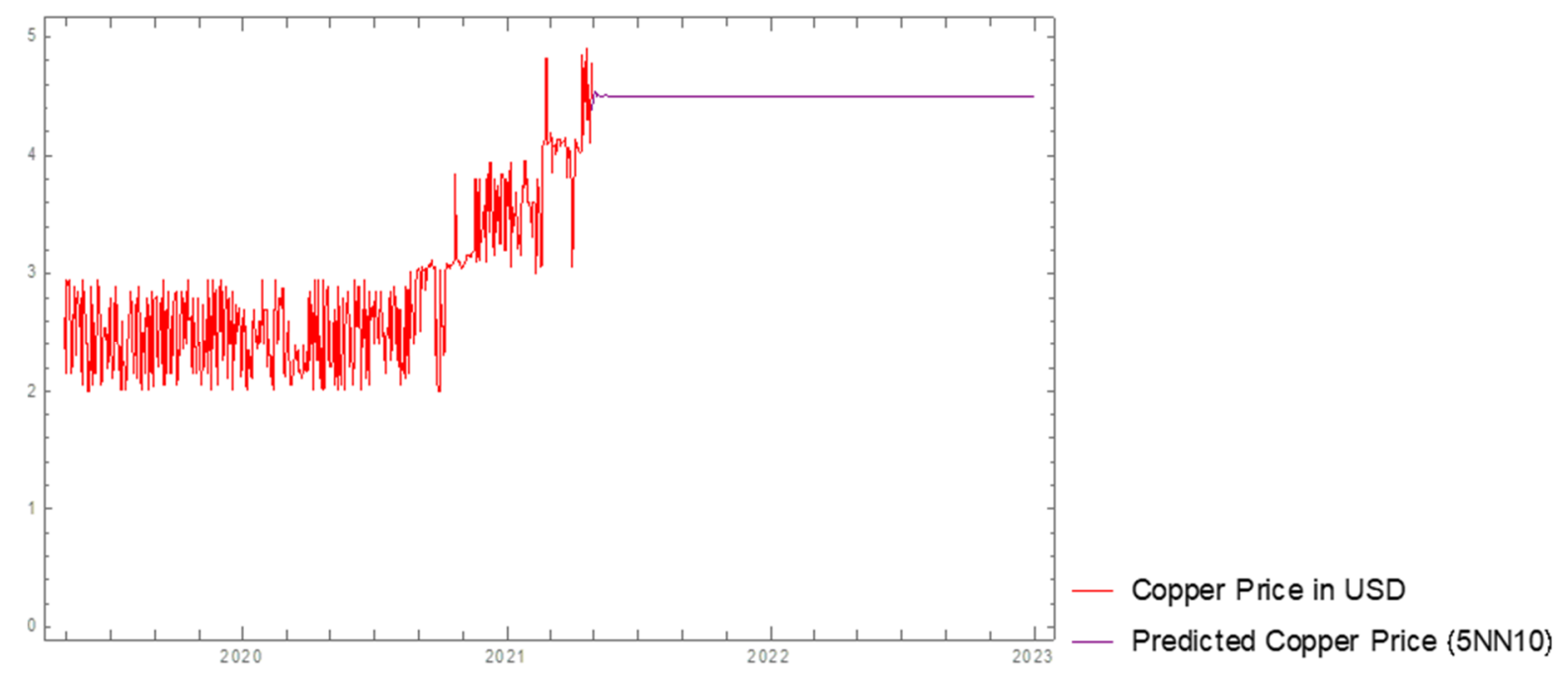

Fig. 11. 5NN10 prediction

Figure 12 shows a more detailed development of copper price in USD from $30^{\text {th }}$ March 2020 to the end of the year 2022. The predictions are made for each day and are marked violet in the period from $1^{\text {st }}$ May 2021 to $31^{\text {st }}$ December 2022. Based on Figure 12, it can be concluded that the predicted development is, to a large extent, constant. 


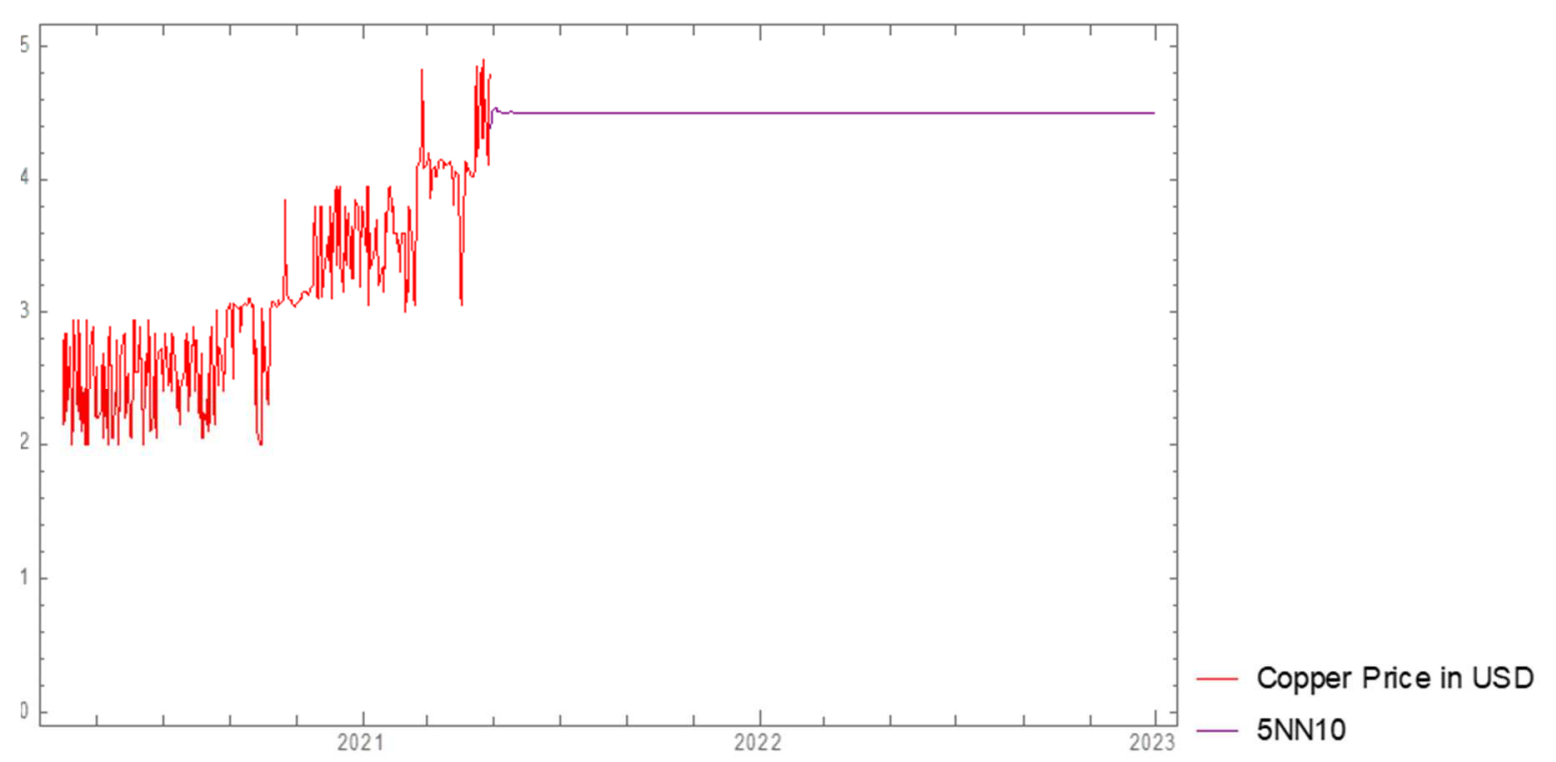

Fig. 12. Development from $30^{\text {th }}$ March 2020 to $31^{\text {st }}$ December 2022

Comparison. After carrying out the two experiments, where one basic dataset was the time series from 1959 to 2021 and the second dataset was the time series from 2019 to 2021, it can be concluded that more precise results were obtained when the shorter time series (Experiment 2) was used as a basis for predicting the future development. In the case of the longer time series, less precise results can be expected, as there were many extreme values that decrease the overall quality of the prediction and thus significantly extending the critical range of values.

Volatility of future development. The results of the predicted volatility between May 2021 and December 2022 are represented in the form of a number in Table 9. The graphical representation of the volatility development is presented in Figure 13.

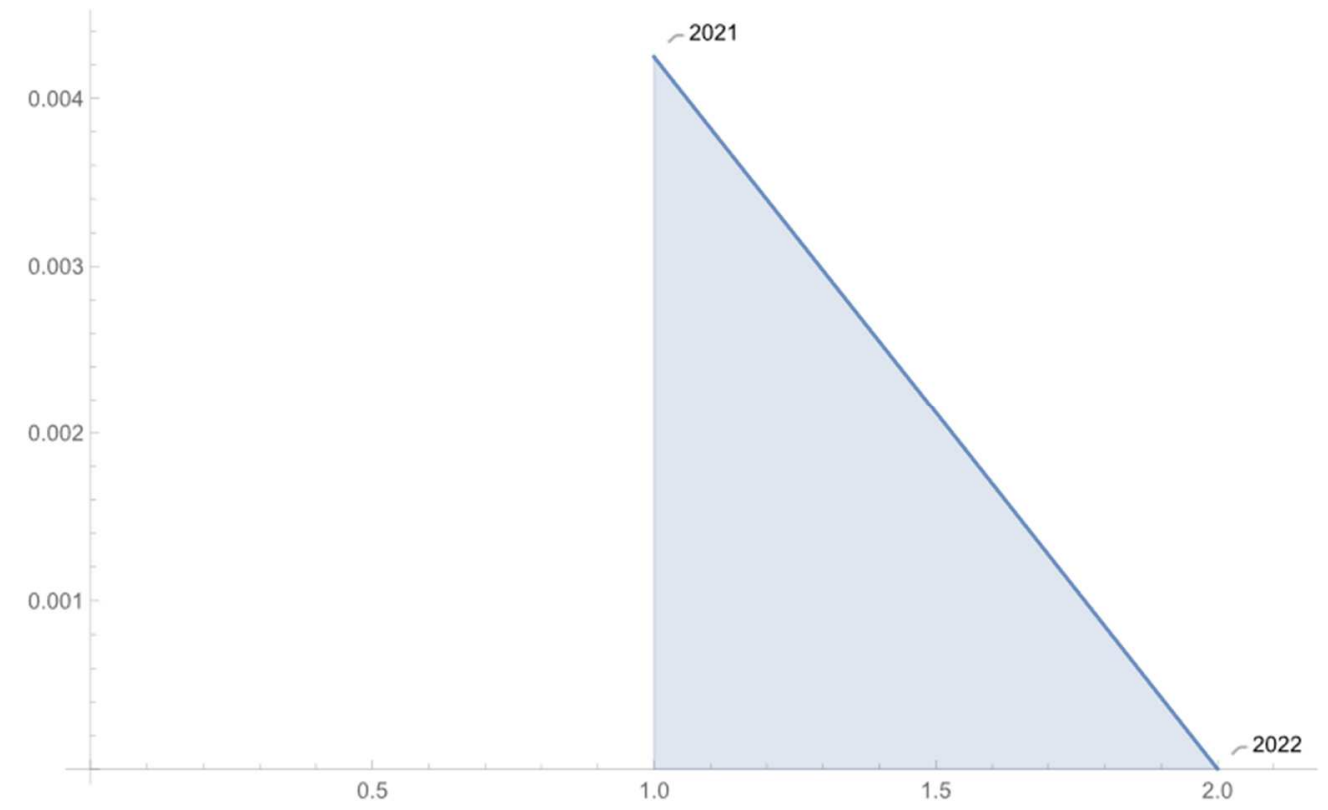

Fig. 13. The volatility of future development of copper prices from 2021 to 2022

Tab. 9. Predicted volatility 2021-2022

\begin{tabular}{cc} 
Year & Volatility \\
\hline 2021 & 0.004248 \\
2022 & 0 \\
\hline
\end{tabular}




\section{Discussion}

RQ1: What is the price volatility of copper in the period from July 1959 to the end of April 2021 ?

The response to this research question can be found in the first part of the presented results, where the development of the copper price volatility is graphically illustrated; the table shows the annual volatility values. The lowest volatility was recorded in the years 1960-1963, where the volatility value is close to zero. This is probably due to the commencing development of this market and the very beginnings of trading with this commodity, where there were no fluctuations in the price of this commodity. The volatility of copper prices achieves its highest value in the year 2008 (0.833669). It can be concluded that the volatility was probably most influenced by the financial crisis, which affected the financial markets primarily. Such a high value of annual volatility was caused by a sharp decrease in copper price due to economic recession. The movement of copper price is a good indicator of future economic development since copper is an important commodity both for the construction industry and the consumer goods sector. At the turn of September 2008, the copper price fell sharply due to the slowdown in the economic development, during which even the activity in the construction and consumer goods sectors was reduced, and thus the demand for copper decreased significantly. At the end of December 2008, it achieved its minimum of USD/1,3150 per one pound. In the following months, the copper price started to grow, which reflected the economic recovery in that period; the increase in copper price was primarily due to the recovery of demand from China. This is confirmed by Langumier (2009), who states that copper price in the last months of 2008 was constantly decreasing; compared to the average prices in 2008, the impact of the recession on the global copper demand and the confidence of investors caused a $50 \%$ increase in the price in the first three years of the current year. However, the prices decreased only slightly for more than three months. Despite the pessimistic economic outlook, starting in mid-February 2009, with the renewed pressure of Chinese demand for copper and dollar depreciation, the copper price started to grow again, reaching its maximum of USD 5200 / $t$ in early June (which means a huge 90\% increase compared to the minimum recorded in December 2008).

Dehghani \& Bogdanovic (2018) also add that on the one hand, the crisis had disturbed the balance of supply and demand for this commodity, which lead to the surplus of supply and inventories. On the other hand, it caused a capital flight from the copper market. Copper price thus decreased from USD 8985/ t to ca. USD 3000/t between mid-2008 and early 2009. For this reason, many mines and smelters were temporarily closed, and many projects were cancelled or suspended. In the following period, the positive performance of China's economy and economic incentives lead to the increase in copper price by $140 \%$ (USD 7400/t).

RQ2: What will be the price movement of copper from May 2021 to December 2022?

The development of copper prices with a subsequent prediction from May 2021 to December 2022 was examined in the first phase (time series smoothing) by means of two experiments. The first experiment concerned the prediction of the development using the complete time series (1959-2021); the second experiment used a shortened time series (2019-2021). The results of both experiments indicate that the shorter time series is a more suitable basis for predicting the future development of copper price for the period of May 2021 - December 2022. The subsequent prediction of future values was thus based on the shortened time series 2019-2021. The results showed that the neural network 5NN10L with the LSTM layer and considered 10-day lag is the most suitable network for predicting the development of future copper price values. Previous research conducted by Wang et al. (2019), who used three widely used methods of ANN, BPNN, RBFNN, and ELM for predicting copper prices after the reconstruction of the original data, and examined the predictive power of the proposed methods PVNANN using the published data on the spot prices of copper from the New York Commodity Exchange (COMEX), concluded that compared to the conventional methods of ANN, the proposed hybrid methods of PVN-ANN could provide quality prediction both in terms of the level and directional predictions. This result clearly demonstrates the efficiency of the proposed hybrid predictive methods in identifying the basic non-linear patterns of international copper price behaviour. The higher efficiency of hybrid methods is confirmed by $\mathrm{Hu}$, Ni \& Wen (2020), whose results show that predictions made by GARCH may serve as informative features to significantly increase the predictive power of the model of the neural network and that the integration of LSTM and ANN networks is an efficient approach to create useful structures of deep neural networks to improve the predictive power. García \& Kristjanpoller (2019) proposed a set of adaptive and non-adaptive models consisting of parametric models of time series, other non-parametric models using in the field of soft computing, and hybrid combinations of these models, and examined the accuracy of these models when predicting monthly volatility of copper prices. The results show that predicting using adaptive methods is essential for achieving robust and improved performance. The Adaptive-GARCH - FIS specification showed the best predictive power. Even in this case, it is the improvement of the ability to predict using hybrid models, where the application of artificial intelligence was crucial to achieving outstanding results. First, it improved predictions made by other models, which lead to the increase in the predictive power by $20 \%$, and up to $40 \%$ in the case of the Adaptive Fuzzy Inference Systems models, thus outperforming other commonly used models; on the other hand, it created an additional tool to solve complex problems, such as using Terasvirtian test to detect non-linear relationships and GA for solving big problems. 
The resulting predicted development of daily copper prices in our research can be described as largely constant. The correctness of this result can be disputed since the historical development of copper prices indicate that there has been no such a constant development of prices over a period longer than one year. The prediction can thus be considered inconclusive. It is worth considering a more detailed analysis of the prediction model configuration or adding another component, thus creating a hybrid model. As for the possibility to predict the future development of copper prices, it is not possible to start from the development of copper price during the economic crisis, which started in 2008, because the demand for copper decreased in this period. However, the Covid crisis in the year 2020 has a different character. Copper, specifically copper oxide, is used as a virus and bacteria deactivator; compared to silver, it is more easily accessible and less expensive to use. The demand for copper thus increase in the Covid crisis, and so does its price. Therefore, it is not possible to base our predictions on the historical development during the 2008 economic crisis.

Based on the predictions made using neural networks, it can be expected that copper price will range between USD 4.5 and 4.6 until the end of the year; it will thus be relatively constant, which enables to plan both the extraction of this metal and production.

RQ3: What will be the volatility of the price movement of copper from May 2021 to December 2022?

The results show that the annual volatility of copper prices between May 2021 and December 2022 will equal 0.004248 in 2021; in 2022, it will be 0 . Here, a fuzzy approach can be used. Low or even zero values of volatility were recorded mainly at the beginning of the time series (the years 1960-3). In the case of predicting the development of volatility for the years 2021 and 2022, however, the prediction of copper price development is based on the shorter time series. As mentioned in the previous chapters, the prediction for the year 2022 appears to be constant. The predicted volatility will thus logically be zero, as there is no movement in the prices.

\section{Conclusion}

The article aimed at translating the past price movement of copper to the potential future trend of the time series until the end of 2022. The experiment involved prediction models built on artificial neural networks - NN with LSTM layer with a ten-day delay. The objective was fulfilled by exploring short historical time series (20192021). We reliably predicted the price movement of copper and successfully found the answer to the second research question. The first and third research question dealt with the time series trend and its prediction. Upon detailed scrutiny of the price volatility from 1959 to 2021, we predicted the trend to the end of 2022, concluding that the future annual volatility value will equal zero in 2022. Yet, the forecast is not very reliable regarding the historical trend of the price volatility of this time series.

Rather than that, the research results can be useful to competitors, e.g. brokers, on the commodity market or professionals focusing on the trade with the goods. The obtained findings may navigate the dealers through the treacherous market conditions; experts, on the other hand, can learn from the analysis to effectively monitor key factors such as supplies of copper in copper mines, the trend of the economic crisis brought about by the coronavirus pandemic in Europe, Asia and South America. These continents abound with the biggest mines with copper ore. The business experts will also be able to promptly respond to the potential demand from China. Donga, Tukkera \& Van der Voeta (2019) argue that the most populated Asian country has a tremendous impact on the price of copper thanks to the rapid economic development in the last decades, including high production capacity and heavy consumption of copper. The country became the world's largest consumer of copper in 2002. China's share of the global demand for copper increased from $20 \%$ in 2006 to $46 \%$ in 2016, including the incremental year-to-year growth. The predicted values of the monitored price volatility of copper obtained from the research refer only to low or zero price volatility of copper on the market. Predictions that do not indicate big movement in the month of May and June 2021 achieved the same results, showing only constant zero volatility. Overall, we may conclude that the price of copper will be gently swinging between 4.5 and 4.6 USD. A relatively stable price allows careful advance planning of copper mining and a follow-up trade with this commodity.

The above-mentioned findings confirm that the devised methodology is broadly applicable for predicting prices of copper, yet the predicted period must not exceed several months. The technique has so far been used only to forecast prices of copper and the price volatility of copper. However, the proposed model may also be useful for predictions in different spheres such as controlling, economics, production etc. The article is limited to an attempt to make a medium-term forecast, rather than getting stuck only in short-term prognoses, as it is in the event of Astudilla et al. (2020), and disregards other variables that influence the price movement of copper. The research may thereby continue by combining hybrid prediction models with artificial intelligence units of comparing various types of extended prediction models. 


\section{References}

Abraham, E. R., Mendes dos Reis, J. G., Vendrametto, O., Oliveira Costa Neto, P. L. de, Carlo Toloi, R., Souza, A. E. de and Oliveira Morais, M. de. (2020). Time series prediction with artificial neural networks: An analysis using Brazilian soybean production. Agriculture, 10(10), 1-18. https://doi.org/10.3390/agriculture10100475

Adebiyi, A. A., Adewumi, A. O., and Ayo, C. K. (2014). Comparison of ARIMA and artificial neural networks models for stock price prediction. Journal of Applied Mathematics, 2014, 1-7. https://doi.org/10.1155/2014/614342

Alipour, A., Khodayari, A. A. and Jafari, A. (2019). Modeling and prediction of time-series of monthly copper prices. International Journal of Mining and Geo-Engineering, 53(1), 91-97.

Astudillo, G., Carrasco, R., Fernández-Campusano, C. and Chacón, M. (2020). Copper price prediction using support vector regression technique. Applied Sciences, 10(19). https://doi.org/10.3390/app10196648

Brabenec, T., Šuleř, P., Horák, J. and Petráš, M. (2020). Prediction of the future development of gold price. Acta Montanistica Slovaca, 25(2), 250-262. https://doi.org/10.46544/AMS.v25i2.11.

Carrasco, R., Vargas, M., Soto, I., Fuentealba, D., Banguera, L. and Fuertes, G. (2018). Chaotic time series for copper's price forecast. Digitalisation. Innovation, and Transformation, 278-288. https://doi.org/10.1007/978-3-319-94541-5_28

Comtrade, U. N. (2016). International Trade Statistics Yearbook. New York: United Nations.

Dehghani, H. and Bogdanovic, D. (2018). Copper price estimation using bat algorithm. Resources Policy, 55, 5561. https://doi.org/10.1016/j.resourpol.2017.10.015

Dong, D., Tukker, A. and Van der Voet, E. (2019). Modeling copper demand in China up to 2050: A business-asusual scenario based on dynamic stock and flow analysis. Journal of Industrial Ecology, 23(6), 1363-1380. https://doi.org/10.1111/jiec.12926

Díaz-Borrego, F. J., Escobar-Peréz, B. and Miras-Rodríguez, M. del M. (2021). Estimating copper concentrates benchmark prices under dynamic market conditions. Resources Policy, 70. https://doi.org/10.1016/j.resourpol.2020.101959

Díaz-Borrego, F. J., Miras-Rodríguez, M. del M. and Escobar-Pérez, B. (2019). Looking for accurate forecasting of copper TC/RC benchmark levels. Complexity, 2019, 1-16. https://doi.org/10.1155/2019/8523748

García, D. and Kristjanpoller, W. (2019). An adaptive forecasting approach for copper price volatility through hybrid and non-hybrid models. Applied Soft Computing, 74, 466-478.

Glöser, S., Soulier, M. and Tercero Espinoza L. A. (2013). Dynamics analysis of global copper flows. Global stocks, postconsumer material flows, recycling indicators, an uncertainty evaluation. Environmental Science \& Technology, 47(12), 6564-72. https://doi.org/10.1021/es400069b

$\mathrm{Hu}$, Y., Ni, J. and Wen, L. (2020). A hybrid deep learning approach by integrating LSTM-ANN networks with GARCH model for copper price volatility prediction. Physica A: Statistical Mechanics and its Applications, 557. https://doi.org/10.1016/j.physa.2020.124907

Chen, Y., He, K. and Zhang, C. (2016). A novel grey wave forecasting method for predicting metal prices. Resources Policy, 49, 323-331. https://doi.org/10.1016/j.resourpol.2016.06.012

International Copper Study Group. (2016). The world copper factbook 2016. Portugal.

Khashei, M. and Bijari, M. (2010). An artificial neural network (p,d,q) model for timeseries forecasting. Expert Systems with Applications, 37(1), 479-489. https://doi.org/10.1016/j.eswa.2009.05.044

Kingma, D. P. and Ba, J. L. (2015). Adam: A method for stochastic optimization. In 3rd International Conference for Learning Representations, San Diego.

Kriechbaumer, T., Angus, A., Parsons, D. and Rivas Casado, M. (2014). An improved wavelet-ARIMA approach for forecasting metal prices. Resources Policy, 39, 32-41. https://doi.org/10.1016/j.resourpol.2013.10.005

Kulkarni, S. and Haidar, I. (2009). Forecasting model for crude oil price using artificial neural networks and commodity futures prices. arXiv preprint arXiv:0906.4838.

Kurumatani, K. (2020). Time series forecasting of agricultural product prices based on recurrent neural networks and its evaluation method. SN Applied Sciences, 2(8). https://doi.org/10.1007/s42452-020-03225-9

Langumier, F. (2009). World Commodity Prices 2009 to Mid-2011. AIECE Commodity Group Report.

Liu, C., Hu, Z., Li, Y. and Liu, S. (2017). Forecasting copper prices by decision tree learning. Resources Policy, 52, 427-434. https://doi.org/10.1016/j.resourpol.2017.05.007

Ly, R., Traore, F. and Dia, K. (2021). Forecasting commodity prices using long short-term memory neural networks. arXiv preprint arXiv:2101.03087.

Macrotrends. (2021). Copper Prices: 45 Year Historical Chart. Macrotrends: The Premier Research Platform for Long Term Investors. Retrieved June 6, 2021, from https://www.macrotrends.net/1476/copper-priceshistorical-chart-data'\%3eSource\%3c/a 
Machová, V., Krulický, T. and Horák, J. (2020). Comparison of neural networks and regression time series in estimating the development of the afternoon price of gold on the New York stock exchange. Social and Economic Revue, 2020(1), 61-72.

Ni, T. (2019). Data analysis and machine learning: On long memory commodity time series (Doctoral dissertation, University of Liverpool).

Sadefo Kamdem, J., Bandolo Essomba, R. and Njong Berinyuy, J. (2020). Deep learning models for forecasting and analyzing the implications of COVID-19 spread on some commodities markets volatilities. Chaos, Solitons \& Fractals, 140. https://doi.org/10.1016/j.chaos.2020.110215

Sánchez Lasheras, F., de Cos Juez, F. J., Suárez Sánchez, A., Krzemień, A. and Riesgo Fernández, P. (2015). Forecasting the COMEX copper spot price by means of neural networks and ARIMA models. Resources Policy, 45, 37-43. https://doi.org/10.1016/j.resourpol.2015.03.004

Sezer, O. B., Gudelek, M. U. and Ozbayoglu, A. M. (2020). Financial time series forecasting with deep learning: A systematic literature review. Applied Soft Computing, 90. https://doi.org/10.1016/j.asoc.2020.106181

Sharma, R., Saxena, A. and Vagrecha, K. (2015). Supply chain optimization of zinc industry: Opportunities, strategies and challenges. Global Journal of Enterprise Information System, 7(3), 62-70. https://doi.org/10.18311/gjeis/2015/6581

Siami-Namini, S., Tavakoli, N. and Siami Namin, A. (2018). A Comparison of ARIMA and LSTM in forecasting time series. In 2018 17th IEEE International Conference on Machine Learning and Applications (ICMLA) (pp. 1394-1401). IEEE. https://doi.org/10.1109/ICMLA.2018.00227

Šuleř, P., Rowland, Z. and Krulický, T. (2021). Evaluation of the accuracy of machine learning predictions of the Czech Republic's exports to the China. Journal of Risk and Financial Management, 14(2). https://doi.org/10.3390/jrfm14020076

Tapia Cortez, C. A., Coulton, J., Sammut, C. and Saydam, S. (2018). Determining the chaotic behaviour of copper prices in the long-term using annual price data. Palgrave Communications, 4(1). https://doi.org/10.1057/s41599-017-0060-x

Vochozka, M. (2018). Comparison of neural networks and regression time series in estimating the development of the afternoon price of palladium on the New York stock exchange. Trends Economics and Management, 11(30), 73-83. https://doi.org/10.13164/trends.2017.30.73

Vochozka, M. and Horák, J. (2019). Comparison of neural networks and regression time series when estimating the copper price development. In Sustainable Growth and Development of Economic Systems: Contradictions in the Era of Digitalization and Globalization; Contributions to Economics (pp. 169-181). Springer.

Vochozka, M., Vrbka, J. and Šuleř, P. (2020). Bankruptcy or success? The effective prediction of a company's financial development using LSTM. Sustainability, 12(18). https://doi.org/10.3390/su12187529.

Wang, C., Zhang, X., Wang, M., Lim, M. K. and Ghadimi, P. (2019). Predictive analytics of the copper spot price by utilizing complex network and artificial neural network techniques. Resources Policy, 63. https://doi.org/10.1016/j.resourpol.2019.101414

\section{Appendix: NN with the best results}

\section{Time series from the year 1959}

Time series lag by 10 trading days

\begin{tabular}{|c|c|c|c|c|c|}
\hline Network & Performance & $\begin{array}{c}\text { Number of Matrix } \\
\text { Members }\end{array}$ & $\begin{array}{l}\text { 1. Activation } \\
\text { Function }\end{array}$ & $\begin{array}{l}\text { 2. Activation } \\
\text { Function }\end{array}$ & $\begin{array}{l}\text { 3. Activation } \\
\text { Function }\end{array}$ \\
\hline 1NN10 & 0.986710 & 378 & ArcTan & Ramp & Sin \\
\hline 2NN10 & 0.986714 & 41 & Ramp & Sin & ArcTan \\
\hline $3 N N 10$ & 0.986762 & 203 & Ramp & Ramp & Sin \\
\hline 4NN10 & 0.986798 & 230 & ArcTanh & ArcTan & Sin \\
\hline 5NN10 & 0.986900 & 21 & ArcTan & Ramp & Ramp \\
\hline
\end{tabular}

Time series lag by 20 trading days

\begin{tabular}{|c|c|c|c|c|c|}
\hline Network & Performance & $\begin{array}{c}\text { Number of Matrix } \\
\text { Members }\end{array}$ & $\begin{array}{l}\text { 1. Activation } \\
\text { Function }\end{array}$ & $\begin{array}{l}\text { 2. Activation } \\
\text { Function }\end{array}$ & $\begin{array}{l}\text { 3. Activation } \\
\text { Function }\end{array}$ \\
\hline 1NN20 & 0.986596 & 110 & Ramp & LogisticSigmoid & Sin \\
\hline 2NN20 & 0.986600 & 146 & Ramp & ArcTan & Sin \\
\hline 3NN20 & 0.986618 & 129 & Ramp & LogisticSigmoid & Tanh \\
\hline 4NN20 & 0.986636 & 59 & ArcTan & Ramp & $\operatorname{Sin}$ \\
\hline 5NN20 & 0.986777 & 94 & Ramp & ArcTanh & Tanh \\
\hline
\end{tabular}

Time series lag by 30 trading days

\begin{tabular}{cccccc}
\hline Network & Performance & $\begin{array}{c}\text { Number of Matrix } \\
\text { Members }\end{array}$ & $\begin{array}{c}\text { 1. Activation } \\
\text { Function }\end{array}$ & $\begin{array}{c}\text { 2. Activation } \\
\text { Function }\end{array}$ & $\begin{array}{c}3 . \text { Activation } \\
\text { Function }\end{array}$ \\
\hline 1NN30 & 0.986761 & 356 & ArcTan & Ramp & Sin
\end{tabular}




\begin{tabular}{ccccc}
\hline & & & \\
2NN30 & 0.986763 & 58 & Ramp & ArcTan \\
3NN30 & 0.986834 & 126 & Ramp & Sin \\
4NN30 & 0.986868 & 98 & Ramp & Ramp \\
5NN30 & 0.986914 & 138 & Ramp & ArcTan \\
\hline
\end{tabular}

Time series from the year 2019

Time series lag by 10 trading days

\begin{tabular}{|c|c|c|c|c|c|}
\hline Network & Performance & $\begin{array}{c}\text { Number of Matrix } \\
\text { Members }\end{array}$ & $\begin{array}{l}\text { 1. Activation } \\
\text { Function }\end{array}$ & $\begin{array}{l}\text { 2. Activation } \\
\text { Function }\end{array}$ & $\begin{array}{l}\text { 3. Activation } \\
\text { Function }\end{array}$ \\
\hline 1NN10 & 0.916636 & 92 & Tanh & Ramp & Ramp \\
\hline 2NN10 & 0.918096 & 69 & Ramp & ArcTan & Ramp \\
\hline $3 \mathrm{NN} 10$ & 0.920842 & 130 & Ramp & Sin & ArcTan \\
\hline $4 \mathrm{NN} 10$ & 0.922938 & 87 & Ramp & Ramp & Sin \\
\hline $5 \mathrm{NN} 10$ & 0.923595 & 59 & Ramp & Tanh & Sin \\
\hline
\end{tabular}

Time series lag by 20 trading days

\begin{tabular}{|c|c|c|c|c|c|}
\hline Network & Performance & $\begin{array}{c}\text { Number of Matrix } \\
\text { Members }\end{array}$ & $\begin{array}{l}\text { 1. Activation } \\
\text { Function }\end{array}$ & $\begin{array}{l}\text { 2. Activation } \\
\text { Function }\end{array}$ & $\begin{array}{l}\text { 3. Activation } \\
\text { Function }\end{array}$ \\
\hline 1NN20 & 0.914598 & 152 & ArcTan & ArcTan & Ramp \\
\hline 2NN20 & 0.915252 & 46 & Ramp & Tanh & Tanh \\
\hline 3NN20 & 0.917557 & 94 & Ramp & Tanh & Tanh \\
\hline 4NN20 & 0.917965 & 71 & Ramp & ArcTan & ArcTan \\
\hline $5 \mathrm{NN} 20$ & 0.921466 & 106 & Ramp & Sin & Ramp \\
\hline
\end{tabular}

Time series lag by 30 trading days

\begin{tabular}{|c|c|c|c|c|c|}
\hline Network & Performance & $\begin{array}{c}\text { Number of Matrix } \\
\text { Members }\end{array}$ & $\begin{array}{l}\text { 1. Activation } \\
\text { Function }\end{array}$ & $\begin{array}{l}\text { 2. Activation } \\
\text { Function }\end{array}$ & $\begin{array}{l}\text { 3. Activation } \\
\text { Function }\end{array}$ \\
\hline $1 \mathrm{NN} 30$ & 0.910429 & 144 & Tanh & Sin & Ramp \\
\hline 2NN30 & 0.911271 & 112 & Tanh & ArcTan & Ramp \\
\hline $3 \mathrm{NN} 30$ & 0.915636 & 98 & Ramp & ArcTan & Ramp \\
\hline 4NN30 & 0.916220 & 114 & Sin & Sin & Ramp \\
\hline $5 \mathrm{NN} 30$ & 0.921063 & 68 & ArcTan & Ramp & Ramp \\
\hline
\end{tabular}

